\title{
DIGITAL EDUCATION, WORK AND ARTIFICIAL INTELLIGENCE: HEALTH AND LAW
}

\author{
Abílio Azevedo, Universidade do Porto, Patrícia Anjos Azevedo, Politécnico do Porto,
} Portugal

\section{Abstract}

The use and possibilities of artificial intelligence (AI) have been assuming great importance in recent years. This fact led to a greater attention on the topic in various fields, especially in health and law, both in its daily application potential and in learning methods. The aim of this article was to present a brief perspective of the challenges and effects of the AI use in teaching and application on health and law domains. Therefore, to better define the theme it was performed a qualitative methodology of bibliographic review. The applications of artificial intelligence have a great potential in clinical and legal use, facilitating the tasks of those involved by helping to reduce workflow, to avoid errors and in decisionmaking. However, despite these benefits and new opportunities, there are still obstacles regarding regulation and ethical concerns, as well as some reluctance from professionals in their adoption and formal application. In addition, there also the need to proper implement these technologies in learning to keep up the change and the new challenges currently posed, so there is a path that still needs to be followed.

\section{Introduction}

In 1956, at an event entitled "Dartmouth Summer Research Project on Artificial Intelligence", at the University of Dartmouth (Hanover, New Hampshire), the term Artificial Intelligence (AI) was probably used for the first time. The definition given pointed out that $\mathrm{AI}$ intended to make machines capable of learning and performing certain functions that are normally made by humans (Pinnock, McDonald, Ritchie, \& Durning, 2020). To humans, the process of evolution is slow and continuous, from generation to generation, while machines do not have that. In intelligent robotics, which we usually call cognitive robotics, there are already experiences of configuring the machine, its hardware and software, adapting it to the context. For example, in 1959, the Checkers program relied on a process similar to genetic algorithms to learn, over time, playing against yourself. The aim of this article was to present a brief perspective of the challenges and effects of the AI 
use in teaching and application on health and law domains. There are many definitions of AI in literature. For example, AI is the activity devoted to making machines intelligent, being intelligence what enables an entity to function appropriately and with foresight in its environment. Moreover, AI is the field of computer science dedicated to solving cognitive problems commonly associated with human intelligence, such as learning, problem solving, and pattern recognition. AI is also the theory and development of computer systems capable of perform tasks that usually require human intelligence, such as visual perception, speech recognition, decision-making, and translation between languages (Chassignol, Khoroshavin, Klimova, \& Bilyatdinova, 2018). Goksel and Bozkurt (2019), in their article, present more definitions of AI given by several authors. Therefore, to better define the theme, it was performed a qualitative methodology of bibliographic review.

\section{Main context of artificial intelligence (AI)}

There are three approaches to AI: strong AI, weak AI, and pragmatic AI. Through the first approach, it is believed that the computer can think in the same way as humans. According to weak AI, the computer would only need to act as if it were smart. In the pragmatic approach, it does not matter if the machines look like humans or not, but what use can be made of them.

Recent achievements coming from AI tools provoke increasing curiosity, generating some discomfort, especially about the possibility of AI replacing human work or the possibility that the machine may think like a human. The idea against treating robots like humans rests on epistemological and ontological arguments. These arguments relate to whether machines can think (they cannot think properly; they react to the input information inserted by humans) and what to be human means. It may be easy to assume that AI is rapidly becoming super intelligent, and gain all the good and evil powers awarded to it in popular culture, which is not the case. AI systems are very limited, and there are technical, social, scientific, and conceptual limits to what they are able to do (Tuomi, 2018). AI companies continue to find ways of developing technology that will manage laborious tasks in different industries for better speed and accuracy. Now, software code controls our lives. Is Man playing gods?

\section{Vital technologies using Al}

Firstly, let us say that AI is an umbrella term, so it has sub-branches, like Machine Learning (ML). AI is a concept that points to the direction we are headed, not a position we have already reached; therefore, we need to specify it more precisely, with notions like ML. At the most primary level, machine learning search to develop methods for computers to improve their performance at certain tasks based on observed data to make future 
predictions enabling the extraction of meaningful patterns from examples, which is a component of human intelligence (Erickson, Korfiatis, Akkus, \& Kline, 2017; Goksel \& Bozkurt, 2019).

In second place, Deep Learning (DL), a most recent domain of AI enables computers to learn and detect patterns in data without being explicitly programmed (Carter et al., 2020). Thirdly, the idea of machines having the same characteristics of human intelligence induces the sense that we are in a science fiction movie, being unable to decide whether the person with whom we communicate is a real person or instead a virtual device, is indeed evidence that DL has taken place in science (Goksel \& Bozkurt, 2019).

In fourth place, Natural Language Processing (NLP), also known as computational linguistics, is a subfield of computer science, which uses computational techniques to learn, understand, and produce human language content. The assistants are used to complete a task controlled by software which has an expanded and optimized database algorithm.

\section{The impact of Al on learning, teaching and education: challenges and opportunities}

Computing can provide the personal services of a tutor accessible to all schoolchildren, teens and adults. Digital education can bring efficiency gains provided by automation and intelligent tutoring. Automation represents a superior ability to achieve desirable goals such as the personalization of learning, flexibility and support of social learning. One of the challenges while teaching students is that everyone has a different "momentum" of learning and understanding of instructions and therefore, those who are already ahead of the material could easily be bored, while others might be completely lost in new terms and phenomena. AI provides a possibility to avoid this problem, namely, by the use of personalized learning (Chassignol, Khoroshavin, Klimova, \& Bilyatdinova, 2018).

Nevertheless, it is ironic that the taking into account a student's personality, style of learning and level of engagement is posited as a goal for the next few decades of education, when human teachers have been largely adept at working to this particular configuration of need for decades, if not centuries (Bayne, 2015).

Recently, countless different interactive educational technologies are becoming popular as students use tablets instead of copybooks, teachers utilize different learning platforms such as Google Classroom, Edmodo, Power School, Moodle and there are a large number of Massive Open Online Courses (MOOCs) for the online study such as coursera.com being accessible 24 hours a day, whenever you want to revise information (Chassignol et al., 2018; Khay-Guan, 2019) 
However, teaching methods and means of assessments remain traditional being represented by lectures, laboratory works, practical exercises, tutorials. Alternatively, students need to drive the conversation, and adapting to new information as the discussion moves forward. Instead, projects, exams, class participations are used in the same course, which gives an opportunity to deliver more objective grade (Klimova, Bilyatdinova, \& Karsakov, 2018). Automated methods are not undesirable (on the contrary, the computational turn in education is fundamental), but the terms on which they are proposed are driven by a productivity-oriented solutionism which has been critiqued for decades now (Bayne, 2015).

Teaching in higher education needs to assume the big questions addressed by critical post humanism. How can we continue to value teaching within an algorithmic culture established by the new potentials of computation and digital data? Teacherbot embodies one way of approaching this question and others (Bayne, 2015). However, where does it leave the human teacher? Let us say that any teacher that can be replaced by a machine should be a teacher.

While a human instructor often works one-on-one, for a specific duration and in constrained spaces, interactive learning environments can be cooperative, omnipresent, and portable. Simply speaking, Interactive Learning Environment (ILE) have unique affordances that human instructors do not, and the next generation of systems should influence those affordances to support learning anytime, anywhere, by anyone (Roll \& Wylie, 2016).

The speed of technological change will be very fast, and it will generate high pressure to transform educational practices, institutions, and policies. It is therefore imperative to understand the potential impact of AI on learning, teaching, and education, as well as on policy development since AI could make some functions of education obsolete and emphasize others, potentially enabling also new ways of teaching and learning (Tuomi, 2018). AI can be used to stimulate personalization and better learning outcomes, being also important to regard Data analytics in Education Management Information Systems (EMIS) and the evolution to Learning Management Systems (LMS) (UNESCO, 2019).

AI is now often called the next electricity. The transformative impact of general-purpose technologies, like AI, however, becomes visible only gradually, when societies and economies reinvent themselves as users of new technologies. Technological change also brings social and cultural change that is reflected in lifestyles, norms, policies, social institutions, skills, and the content and forms of education (Tuomi, 2018).

Another important point is that intelligent tutoring systems create a digital profile of a student and provide him with a personal tutor that, again, should increase productivity 
inside a classroom and out of it. Such digital portfolios of learned subjects and topics can be great as well to help employers (Chassignol et al., 2018).

\section{Artificial intelligence in health: work and education}

\section{Al applications in medical fields and health practice}

Fuelled by advances in computing power, data availability, and machine learning techniques, applications of artificial intelligence (AI) are rapidly increasing in a wide range of medical fields for varying purposes (Allen et al., 2019; Becker, 2019). One of the most promising areas of health innovation is the application of artificial intelligence (AI) in medical imaging emerging as one of the most important topics in radiology today (Chan, Bailey, \& Ros, 2020; Pesapane, Codari, \& Sardanelli, 2018).This is due in part to the remarkable progress in image-recognition tasks, which in recent years has seen growth in the amount of sufficient digital data accumulation and availability as well as significant computational power (Mintz \& Brodie, 2019). In addition, that is fairly motivated by the recognition of the significant frequency and clinical impact of human errors in radiology reporting, and the promise that AI can help improve the reliability as well the efficiency of imaging interpretation and analysis.

Artificial intelligence is also being widely used in clinical cancer research due to its feasibility and advantages as well as allowing to perform robotic surgery and to provide personalized treatment plans helping patients and to decrease costs (AminololamaShakeri \& López, 2019; Geis et al., 2019; Huang, Yang, Fong, \& Zhao, 2020; Lakhani et al., 2018). An increasing number of studies illustrate the potential for dramatic changes with the use of AI since image recognition technology might make predictions or recognize diseases as effectively as or even better than physicians showing AI algorithms matching human performance in medicine (Krittanawong, 2018; Mazurowski, 2019).

Current algorithms of artificial intelligence, have been used for several challenging tasks, such as pulmonary embolism segmentation with computed tomographic (CT) angiography, polyp detection with virtual colonoscopy or CT in the setting of colon cancer, breast cancer detection and diagnosis with mammography, brain tumour segmentation with magnetic resonance (MR) imaging, and detection of the cognitive state of the brain with functional MR imaging to diagnose neurologic disease) (Erickson et al., 2017). When applied to chest radiograph (CXR) reading, these algorithms are able to detect up to 14 common anomalies such as: lung nodule diagnosis, tuberculosis diagnosis, detection of pneumonia and detection of common chest radiograph anomalies (Chassagnon, Vakalopoulou, Paragios, \& Revel, 2020).

One of the first fields of medical imaging that benefited from the introduction of machine learning algorithms techniques was breast imaging (Carter et al., 2020). In the past years 
many studies have been developed about the usage of deep learning algorithms concerning breast cancer detection and identification, including the one by Rodríguez Fernández et al. (2019), that compared the stand-alone performance of an AI system to that of radiologists in detecting breast cancer in digital mammography (DM) were the AI system achieved a cancer detection accuracy comparable to an average breast radiologist in this retrospective setting having higher performance that more than half of the radiologists.

\section{Al applications in medical and health education}

AI will have an direct impact on every aspect of our lives, and there is no reason to believe that medicine and medical education will be spared, being educators' responsibility to prepare themselves and the students for the future with AI, so that quality healthcare can be delivered (Masters, 2019). To date, AI technologies have been used in the medical field by improving clinical workflows, risk assessment, and training (Sheikh \& Fann, 2019).

Technology can be seen in two facets: firstly, how technology supports or assists medical education, and second, how it supports and changes the face of healthcare itself (KhayGuan, 2019). As with other investigations used in clinical practice, students will need to understand evaluative measures such as the recall (sensitivity or the probability that a machine correctly identifies all true positive matches) and positive predictive value (precision or the probability that an outcome categorized by a machine as a positive match is indeed a positive match) of the machines they are using (Pinnock, McDonald, Ritchie, \& Durning, 2020). Even so, technology is already transforming medical education as it serves as a mean to engage and interact with students, broadens networks and allows collaborative work, enables personalized medical education and acts as a leveller (KhayGuan, 2019).

Technology allows the students to personalize medical education since each one can pick an individual scheme of learning, choosing their own materials, including on other medical schools, widening access to those less privileged populations that can access online learning (Khay-Guan, 2019).

As one of the first sub-specialties to broadly discuss the impact of AI on medicine, radiology should therefore take the lead in educating undergraduate students on these emerging technologies, emphasizing the specific challenges that may lay ahead. More specifically, basic knowledge of the technical background of AI in medicine and radiology should be conveyed in terms of what data are needed for which type of task and how AI algorithms should be evaluated (Pinto dos Santos et al., 2019). 


\section{Ethical considerations of artificial intelligence in health}

Although AI technologies are attracting substantial attentions in medical research, the real-life implementation is still facing obstacles, being regulations the first hurdle (Jiang et al., 2017). Several medical ethics theories described for human beings are being considered (consequentialist, deontological, virtue, among others) as well as the implications of their use within a machine in order to identify the best way to describe and adapt values from humans to machines (Keskinbora, 2019). Therefore, ethical challenges of AI will need to be addressed, including algorithms mirroring human biases, using information on diagnosis or treatment that is not based on adequate evidence and managing the extensive amount of data collected from patient records to preserve patient privacy (Pinnock et al., 2020). AI systems should privilege "data minimization" using only what they need and delete it when it is no longer required, encrypt data in transit and at rest and restrict access to authorized personnel "access control" (Keskinbora, 2019). The ethics of data are fundamental to AI in all the specialties, especially in radiology and reflect trust in acquiring, managing, and assessing data (Geis et al., 2019).

\section{Artificial intelligence in law: work and education}

\section{Al applications in law practice}

Jurists see the relationship between computing and law as something extremely recent. The legal area implies the scientific foundation of politics and law. Reasoning in law can be reduced to computation, which applies not only to numbers, but also to any area of knowledge, since logic, in law, is about adding words to create affirmations and affirmations to form syllogisms. Law is a combination of concepts, and the identification and combination of the most basic concepts would be the key, so that the solution of any conflict could be reduced to a calculation on the possible combinations of the presence and absence of those concepts in the case description.

AI's current legal applications help lawyers to perform due diligence and research, and provide additional insights and shortcuts. More specifically, AI's applications can serve: due diligence, helping to uncover background information; prediction technologies, generating results that forecast a litigation outcome; legal analytics, with the use of data points from past case law, win/loss rates and a judge's history; document automation, in order to create templates and filled out documents based on data input; intellectual property, so that lawyers can draw portfolios and insights from the content; electronic billing, so that billable hours are computed automatically.

The legal professional who knows how to face AI in order to optimize his work will surely be a better lawyer. The great challenge of research in AI in judicial work will be to transpose it as a useful tool for the solution of conflicts without making it an aim in itself. 
In this sense, the use of AI in data search systems, decision-making processes and writing of contracts, for example, must be done with critical reflection. AI will never be enough to solve the problems of our legal culture and we must be careful, even, that it does not deepen them by creating false expectations that, at some point, automatism may release us from thinking.

\section{Al applications in law education}

AI is largely applied to the representation of knowledge and inferences of intelligent agents. There are different logics to represent different dimensions of these processes. For these purposes, it is important that research and university education are open to interdisciplinary and the combination of these sciences, mathematics and law. The novelties powered by AI promise to expand the database access and management capacity; offer better tools for the production of court decisions, petitions and agreements; decrease operating costs and expenses and even the same, in law firms.

These ideas about the progressively more use of technology in law (Legaltech) and also about the way we are working today and will work in the future, led us to the following: Law schools need to understand that the traditional profile didactic-pedagogical that until then provided success to the learning of its students no longer present themselves as the successful formula and the trend is towards the market increasingly demonstrates how retrograde and obsolete this proves to be (Raquel Hogemann, 2018).

It is important to highlight the fact that the use of processing technologies data and digital communication represented a vital gain for both lawyers and the judiciary as a whole (Raquel Hogemann, 2018).

\section{Ethical considerations of artificial intelligence in law}

Ethics is a philosophical discipline, linked (or complementary) to law that studies good and evil and their relationship to morality and human behaviour. Ethics is an idea, a structure or a model of thought and action, a unique concept in abstract terms, but with a variable scope and content. The reason is that the concepts of good or evil, the idea of morality, and models of human behaviour are not perpetual, rigid, or static, but evolve over time and through space (Robles Carrillo, 2020). There is neither a basic social conscience nor a solid and sufficient political determination to face the AI challenge, just as there is also no common language or unique methodology about its uses, skills and objectives. AI can have a positive or negative impact, or both, at the same time, for different audiences or from different perspectives, not having uniform or unanimous assessment of its advantages and/or disadvantages or how to manage them. Overall, the debate is being placed between resistance to change and the sublimation of change implied by AI (Robles Carrillo, 2020). 


\section{Conclusions}

The purpose of this article was to present a brief perspective of the challenges and effects of the artificial intelligence use in teaching and application on health and law fields. AI is already been used and has a great potential in clinical and legal use, facilitating the tasks of involved professionals by helping to reduce workflow, to avoid errors and in decisionmaking. Concerning teaching and learning, digital technology allows students to personalize education using individual organization and promotes equal opportunities. Tutors and institutions need to proper implement, incorporate and promote these technologies in academic curricula. Despite the reported benefits and new possibilities, there are still hurdles regarding regulation and ethical concerns, as well as some reluctance from some professionals in the adoption and real use of AI systems. In order to keep up with the challenges currently posed, there is still a path that needs to be followed. This article will serve to offer a contribution on the discussion about a topic that has been progressively more debated between the scientific community and the general population since the use of such technologies are already present in our everyday lives in a present way.

\section{References}

Allen, B., Seltzer, S. E., Langlotz, C. P., Dreyer, K. P., Summers, R. M., Petrick, N., ... Kandarpa, K. (2019). A Road Map for Translational Research on Artificial Intelligence in Medical Imaging: From the 2018 National Institutes of Health/RSNA/ACR/The Academy Workshop. Journal of the American College of Radiology, 16(9), 1179-1189. https://doi.org/10.1016/j.jacr.2019.04.014

Aminololama-Shakeri, S., \& López, J. E. (2019). The doctor-patient relationship with artificial intelligence. American Journal of Roentgenology, 212(2), 308-310. https://doi.org/10.2214/AJR.18.20509

Bayne, S. (2015). Teacherbot: interventions in automated teaching. Teaching in Higher Education, 20(4), 455-467. https://doi.org/10.1080/13562517.2015.1020783

Becker, A. (2019). Artificial intelligence in medicine: What is it doing for us today? Health Policy and Technology, 8(2), 198-205. https://doi.org/10.1016/j.hlpt.2019.03.004

Carter, S. M., Rogers, W., Win, K. T., Frazer, H., Richards, B., \& Houssami, N. (2020). The ethical, legal and social implications of using artificial intelligence systems in breast cancer care. The Breast, 49, 25-32. https://doi.org/10.1016/j.breast.2019.10.001

Chan, S., Bailey, J., \& Ros, P. R. (2020). Artificial Intelligence in Radiology: Summary of the AUR Academic Radiology and Industry Leaders Roundtable. Academic Radiology, 27(1), 117-120. https://doi.org/10.1016/j.acra.2019.07.031 
Chassagnon, G., Vakalopoulou, M., Paragios, N., \& Revel, M. P. (2020). Artificial intelligence applications for thoracic imaging. European Journal of Radiology, 123(November 2019). https://doi.org/10.1016/j.ejrad.2019.108774

Chassignol, M., Khoroshavin, A., Klimova, A., \& Bilyatdinova, A. (2018). Artificial Intelligence trends in education: A narrative overview. Procedia Computer Science, 136, 16-24. https://doi.org/10.1016/j.procs.2018.08.233

Erickson, B. J., Korfiatis, P., Akkus, Z., \& Kline, T. L. (2017). Machine Learning for Medical Imaging. Radiographics, 505-515.

Geis, J. R., Brady, A. P., Wu, C. C., Spencer, J., Ranschaert, E., Jaremko, J. L., ... Kohli, M. (2019). Ethics of Artificial Intelligence in Radiology: Summary of the Joint European and North American Multisociety Statement. Journal of the American College of Radiology, 16(11), 1516-1521. https://doi.org/10.1016/j.jacr.2019.07.028

Goksel, N., \& Bozkurt, A. (2019). Artificial Intelligence in Education: Current Insights and Future Perspectives. In S. Sisman-Ugur \& G. Kurubacak (eds.), Handbook of Research on Learning in the Age of Transhumanism (pp. 224-236). Hershey, PA: IGI Global. https://doi.org/10.4018/978-1-5225-8431-5.ch014

Huang, S., Yang, J., Fong, S., \& Zhao, Q. (2020). Artificial intelligence in cancer diagnosis and prognosis: Opportunities and challenges. Cancer Letters, 471, 61-71. https://doi.org/10.1016/j.canlet.2019.12.007

Jiang, F., Jiang, Y., Zhi, H., Dong, Y., Li, H., Ma, S., ... Wang, Y. (2017). Artificial intelligence in healthcare: Past, present and future. Stroke and Vascular Neurology, 2(4), 230-243. https://doi.org/10.1136/svn-2017-000101

Keskinbora, K. H. (2019). Medical ethics considerations on artificial intelligence. Journal of Clinical Neuroscience, 64, 277-282. https://doi.org/10.1016/j.jocn.2019.03.001

Khay-Guan, Y. (2019). The future of medical education. Singapore Medical Journal, 60(1), 3-8. https://doi.org/10.11622/smedj.2019003

Klimova, A., Bilyatdinova, A., \& Karsakov, A. (2018). Existing Teaching Practices in Augmented Reality. Procedia Computer Science, 136, 5-15. https://doi.org/10.1016/j.procs.2018.08.232

Krittanawong, C. (2018). The rise of artificial intelligence and the uncertain future for physicians. European Journal of Internal Medicine, 48, e13-e14. https://doi.org/10.1016/j.ejim.2017.06.017

Lakhani, P., Prater, A. B., Hutson, R. K., Andriole, K. P., Dreyer, K. J., Morey, J., ... Hawkins, C. M. (2018). Machine Learning in Radiology: Applications beyond Image 
Interpretation. Journal of the American College of Radiology, 15(2), 350-359. https://doi.org/10.1016/j.jacr.2017.09.044

Masters, K. (2019). Artificial intelligence in medical education. Medical Teacher, 41(9), 976-980. https://doi.org/10.1080/0142159X.2019.1595557

Mazurowski, M. A. (2019). Artificial Intelligence May Cause a Significant Disruption to the Radiology Workforce. Journal of the American College of Radiology, 16(8), 10771082. https://doi.org/10.1016/j.jacr.2019.01.026

Mintz, Y., \& Brodie, R. (2019). Introduction to artificial intelligence in medicine. Minimally Invasive Therapy and Allied Technologies, 28(2), 73-81. https://doi.org/10.1080/13645706.2019.1575882

Pesapane, F., Codari, M., \& Sardanelli, F. (2018). Artificial intelligence in medical imaging: threat or opportunity? Radiologists again at the forefront of innovation in medicine. European Radiology Experimental, 2(1). https://doi.org/10.1186/s41747-0180061-6

Pinnock, R., McDonald, J., Ritchie, D., \& Durning, S. J. (2020). Humans and machines: Moving towards a more symbiotic approach to learning clinical reasoning. Medical Teacher, 42(3), 246-251. https://doi.org/10.1080/0142159X.2019.1679361

Pinto dos Santos, D., Giese, D., Brodehl, S., Chon, S. H., Staab, W., Kleinert, R., ... Baeßler, B. (2019). Medical students' attitude towards artificial intelligence: a multicentre survey. European Radiology, 29(4), 1640-1646. https://doi.org/10.1007/s00330-018$5601-1$

Raquel Hogemann, E. (2018). O futuro do Direito e do ensino jurídico diante das novas tecnologias. Revista Interdisciplinar Do Direito - Faculdade de Direito de Valença, 16(1), 105-115. https://doi.org/10.24859/fdv.2018.1.005

Robles Carrillo, M. (2020). Artificial intelligence: From ethics to law. Telecommunications Policy, (April 2019), 101937. https://doi.org/10.1016/j.telpol.2020.101937

Rodríguez Fernández, A., Triviño Ibáñez, E. M., Gómez Río, M., Pérez Lázaro, J. J., Fernández Ruiz, I., Ramírez Navarro, Á., ... Llamas-Elvira, J. M. (2019). Development of a positron emission tomography risks map [Desarrollo de un mapa de riesgos para la tomografía por emisión de positrones]. Revista Espanola de Medicina Nuclear e Imagen Molecular, 38(1), 38-45. https://doi.org/10.1016/j.remn.2018.09.007

Roll, I., \& Wylie, R. (2016). Evolution and Revolution in Artificial Intelligence in Education. International Journal of Artificial Intelligence in Education, 26(2), 582-599. https://doi.org/10.1007/s40593-016-0110-3 
Sheikh, A. Y., \& Fann, J. I. (2019). Artificial Intelligence: Can Information be Transformed into Intelligence in Surgical Education? Thoracic Surgery Clinics, 29(3), 339-350. https://doi.org/10.1016/j.thorsurg.2019.03.011

Tuomi, I. (2018). The Impact of Artificial Intelligence on Learning, Teaching, and Education Policies for the future. EUR - Scientific and Technical Research Reports. https://doi.org/10.2760/12297

UNESCO. (2019). Artificial intelligence in education: challenges and opportunities for sustainable development. Working Papers on Education Policy, 7, 46. Retrieved from https://en.unesco.org/themes/education-policy- 